\title{
Virtual journal club during the pandemic: a valuable learning tool
}

Jorge Hoegl (iD), Caracas, Venezuela, Caracas, Venezuela; Juliana Rodriguez (D), Bogotá, Colombia, Bogotá, Colombia; Erick Estuardo Estrada (D) , Guatemala City, Guatemala; Monica Heymann, San Salvador, El Salvador and Rene Pareja (i) , Bogotá, Colombia

The term "Journal Club" is attributed to Sir James Paget, in 1835, when in a room of his hospital he gathered colleagues and students to discuss medical publications. However, the first journal club was made official by Sir William Osler, and in 1889 he formally organized the first meetings under that name, at John Hopkins University, to discuss the most important medical publications of that time with the club members. ${ }^{1}$ This tool is an essential part of the medical training of all specialties, especially in resident's educational growth and training, but it certainly depends on a structured organization, a work team, and a leader capable of directing and choosing, in the most objective way, the discussion of the selected article. ${ }^{2}$

With the growing use of technological platforms, greater access to social networks, availability of smart devices, and "anytime, anywhere" access to information, the concept of the traditional journal club has been transformed, giving step to a virtual forum. ${ }^{3}$ Among the benefits of this modality is the possibility of scheduling meetings at convenient times that do not interfere with the daily work routine and direct interaction with colleagues from other regions, in addition to providing an academic and disciplinary benefit.

In December 2019, the first Virtual Journal Club of gynecologic oncology was held in Colombia, with 20 participants (fellows, gynecologic oncologists, and international guests), coordinated by Dr Rene Pareja (Professor of Gynecologic Oncology) and $\mathrm{Dr}$ Juliana Rodriguez (gynecology oncologist and epidemiologist), in order to discuss articles of scientific interest related to the specialty. The activity was conducted weekly, at night, for 1 hour per week. In January 2020, this initiative expanded to other countries including Guatemala, El Salvador, and Venezuela, as well as other

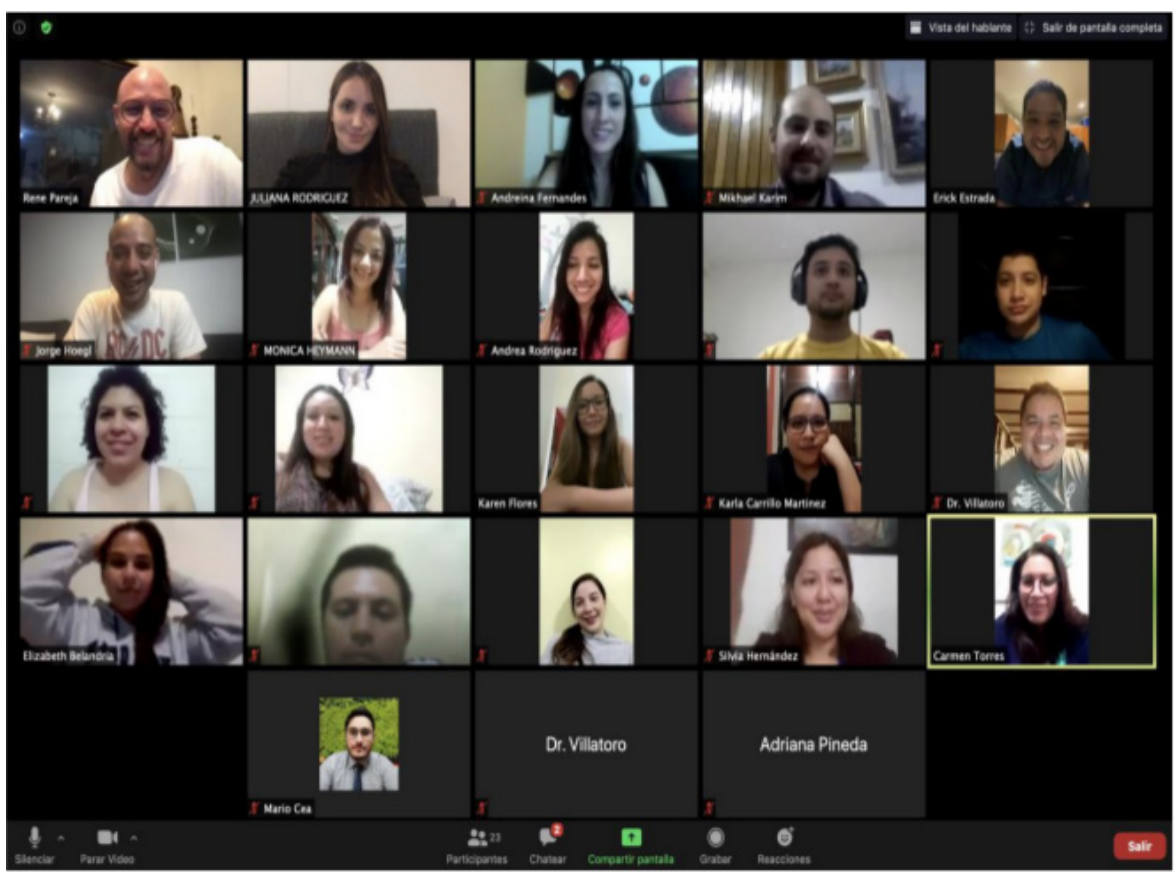

Figure 1 Virtual Journal Club El Salvador-Venezuela.

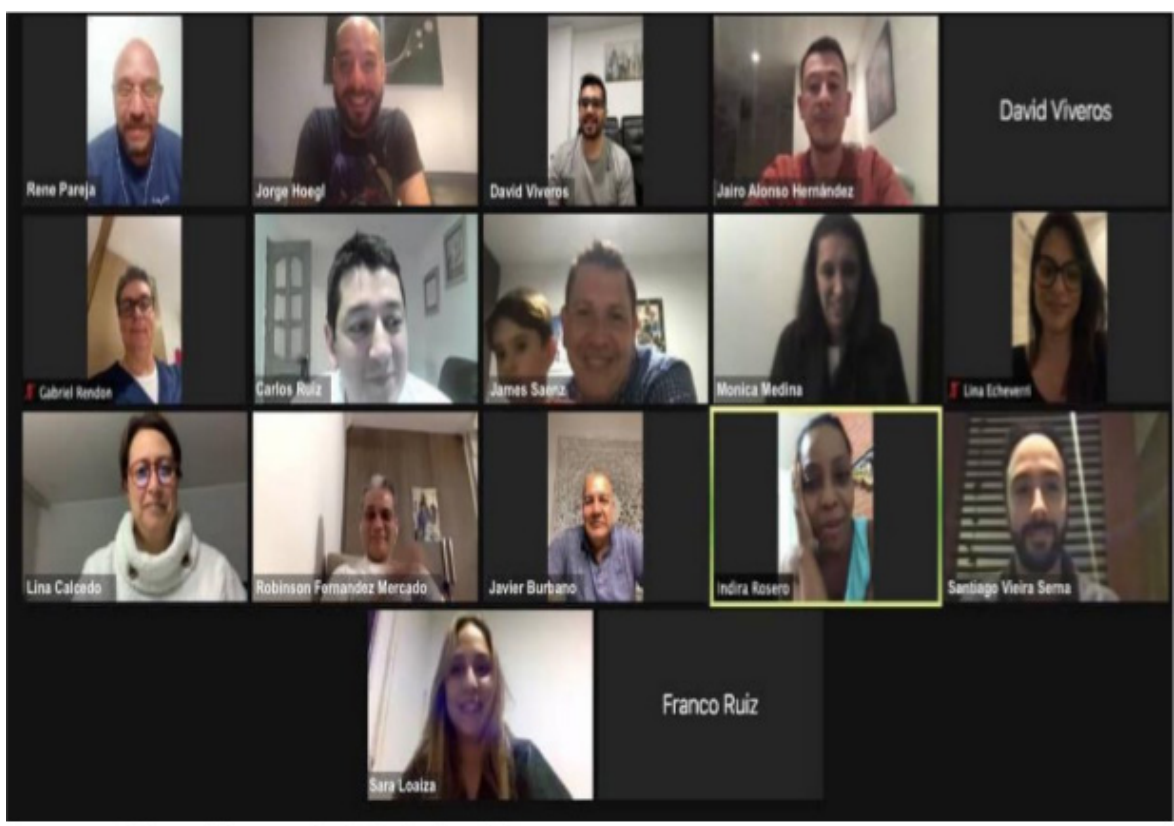

Figure 2 Virtual Journal Club Colombia. 


\section{Corners of the world}

groups in Colombia, taking place twice a month, for 1 hour, with the aim of bringing together gynecologic oncologists and other healthcare providers in female cancer from all over the region (Figures 1 and 2).

To date, a total of nearly 50 physicians (gynecologic oncologists, surgical oncologists, fellows) have gathered and at least six articles are discussed per month. Each article is presented in a structured format and discussed by all participants. These presentations are preceded by a basic course in evidence-based medicine and statistics. This academic session generates a historical precedent in the region, capable of encouraging new generations to understand the importance of comprehensive reading in scientific research, to have global perspectives, to achieve changes in the medical practice of their populations, based on robust evidence and under the guidance of a mentor.

Almost two hundred years after this historic idea of Sir William Osler, and especially in a year such as 2020 in which the COVID-19 pandemic forced social isolation, the virtual journal club continues to be a useful tool in the academic growth of physicians, facilitating communication and learning among professionals of different nationalities.

Correspondence to Dr Rene Pareja, Department of Gynecologic Oncology Instituto Nacional de Cancerología - Calle 1 \#9-85; e-mail: rpareja@cancer. gov.co, Bogotá, Colombia; ajerapener@gmail.com

Twitter Jorge Hoegl @oncohoegl, Juliana Rodriguez @julianalrc, Erick Estuardo Estrada @mderickestrada and Rene Pareja @RParejaGine0nco

Contributors JH, JR, RP: study design; EEE, MH: literature search; JH, JR, EEE, MH, RP: writing of the article. All authors approved the final version of the manuscript.

Funding The authors have not declared a specific grant for this research from any funding agency in the public, commercial, or not-for-profit sectors.

Competing interests None declared.

Patient consent for publication Not required.

Provenance and peer review Commissioned; internally peer reviewed.

(C) IGCS and ESGO 2021. No commercial re-use. See rights and permissions. Published by BMJ.

Check for updates
To cite Hoegl J, Rodriguez J, Estrada EE, et al. Int J Gynecol Cancer Published Online First: [please include Day Month Year]. doi:10.1136/ijgc-2021-002712

Accepted 23 April 2021

Int J Gynecol Cancer 2021;0:1-2.

doi:10.1136/ijgc-2021-002712

\section{ORCID iDs}

Jorge Hoegl http://orcid.org/0000-0003-0063-3871 Juliana Rodriguez http://orcid.org/0000-0002-54724093

Erick Estuardo Estrada http://orcid.org/0000-00025184-556X

Rene Pareja http://orcid.org/0000-0003-0093-0438

\section{REFERENCES}

1 Linzer M. The Journal Club and medical education: over one hundred years of unrecorded history. Postgrad Med J 1987;63:475-8.

2 Gottlieb M, King A, Byyny R, et al. Journal Club in residency education: an evidence-based guide to best practices from the Council of Emergency Medicine residency directors. West $\mathrm{J}$ Emerg Med 2018;19:746-55.

3 Chetlen AL, Dell CM, Solberg AO, et al. Another time, another space: the evolution of the virtual Journal Club. Acad Radiol 2017;24:273-85. 